TP Periodica Polytechnica Mechanical Engineering

61(4), pp. 296-302, 2017

https://doi.org/10.3311/PPme.11149

Creative Commons Attribution (i)

RESEARCH ARTICLE

\section{A Comparative Study of Tool-Pin Profile on Process Response of Friction Stir Welding of AA6082-T6 Aluminium Alloy}

\author{
Kayode Oyedemi ${ }^{1 *}$, Patrick McGrath ${ }^{1}$, Hannalie Lombard ${ }^{1}$, \\ Balázs Varbai ${ }^{2}$
}

Received 16 June 2017; accepted after revision 19 September 2017

\begin{abstract}
This paper presents research work conducted to experimentally establish the process response of two diverse shaped tool-pin profiles for friction stir welding (FSW) AA6082-T6 aluminium. The dwell time was optimised by plunging each tool-pin into a plate sample until the spindle torque stabilised thus ensuring sufficient plasticised material in contact with tool shoulder and the tool-pins. The welds were conducted by employing the optimised dwell time, which in turn revealed a minimised process response time and distance to reach weld stability with respect to (1) the force exerted on the tool-pin in the welding direction, $F_{x}$, and (2) the spindle torque, T, during the welding process. Both $F_{x}$ and $T$ stabilised well within the set (pre-determined) ramp-up distance of $20 \mathrm{~mm}$, indicating that the effective (useful) weld length is maximised. The macrographs also revealed good dynamic material flow within the nugget zone regions and more evident in the nugget zone of the flared tool.
\end{abstract}

\section{Keywords}

friction stir welding, FSW, tool geometry, 6082-T6 aluminum, microhardness, spindle torque, plunge force

\footnotetext{
${ }^{1}$ Department of Mechanical Engineering, Faculty of Engineering, the Built Environment and Information Technology, Nelson Mandela Metropolitan University, PO Box 7700, Port Elizabeth, 6000, South Africa

${ }^{2}$ Department of Materials Science and Engineering, Faculty of Mechanical Engineering, Budapest University of Technology and Economics, H-1111 Budapest, Bertalan Lajos str. 7., Hungary

*Corresponding author, e-mail: Kaypratto@gmail.com
}

\section{Introduction}

Friction Stir Welding (FSW) is a well-established solidstate technique capable of joining similar and dissimilar materials using different joint configurations $[1,2]$. The FSW process has been widely studied over the years since implemented by The Welding Institute (TWI). Among these researches, the FSW of precipitation hardened aluminium alloy have special attention [3-12]. Many experiments conducted in the past dealt with seeking relationships between process parameters and resulting joint integrity [13] while others undertook studies in defining suitable operating windows $[14,15]$. Relationships between process parameters and weld defects have also been studied $[16,17]$. Gap tolerance and its bridge-ability has been given attention in the past but without close consideration on the influence of varying the tool profiles, process parameters and the welding sequence in FSW. The presence of pin re - entrant features influences the pulsating stirring effect [1315]. When welding two abutted plates in FSW, the presence of gap between the faying surfaces of the plates is a reality and common problem for manufacturing reasons. This gap between plates may be due to improper alignment, mismatch or clamping and is limited to a percentage of the plate thickness above which the weld quality will be compromised [18]. In the past, laser welding, arc welding and hybrid welding have been used individually to join parts together especially in automotive components [19]. However, laser welding has a disadvantage when being used for lap welding; the gap between the lapped sheets, which should be controlled very tightly. If the gap is too large, there will be occurrence of burn-through and, if the gap is excessive, the sheet cannot be welded together. Because of this reason, the gap is generally restricted to $0.1 \mathrm{~mm}$ or less for laser welding [19] irrespective of plate thickness. In case of the hybrid welding [19], the gap tolerance is much greater than that of laser welding because the filler wire used in hybrid welding supplies enough weld material to fill the gap. Contrarily, when a gap is present in laser welding with no filler metal, the amount of molten metal tends to be insufficient to fill the gap, resulting to under-fill. Because of this, laser-arc hybrid welding was developed to solve these problems. This method combines 
laser welding and arc welding and it allows a larger gap between lapped sheets than in laser welding, and produces fewer blowholes [19]. Dawes CJ et al. [15] of The Welding Institute recommended that maximum gap tolerance between plates to be joined in FSW to be $10 \%$ of the plate thickness. Recently, a paper [20] was presented at the $8^{\text {th }}$ international Friction Stir Welding symposium. The study made use of Al powder (average particle size: $89 \mu \mathrm{m}$ ) as a filler material for bridging the gap and to increase the hardness of the weld metal. Weld gap of $60 \%$ of the plate thickness was achieved with this $\mathrm{Al}$ powder. A method of varying the advancing speed and the plunge depth was also investigated [13] but with fixed tool profiles. With $2^{\circ}$ tilt angle and a deeper plunge depth, a 20\% gap was successfully welded over. These above-mentioned parameters have a strong effect on the weld's mechanical properties [21].

FSW does not require the use of filler materials therefore; any gap between the abutting surfaces of the weld result to thinning and reduction in the cross-sectional area of the weld [18]. An ability to bridge these gaps without compromising weld integrity will be advantageous. When FSW tool encounters a gap, material can possibly escape (not as flash) but from the processing zone and this causes poor welds due to lack of bonding and insufficient material mixing [18]. Both effects can possibly weaken the weld therefore a method is required to increase gap tolerance while maintaining joint integrity. This method involves the use of novel tool designs and process parameter control to achieve adequate welds. Tool-pin and tool shoulder geometries in creating a joint have been studied but little is known in comparing these different tool profiles to process response of welds in a single study. Previous studies [22] showed that a simple tool pin shape does not produce enough heat. In our paper, a study on possible methods to increase weld gap tolerance requirements in FSW of $8 \mathrm{~mm}$ thick AA6082-T6 aluminum alloy was investigated and evaluated. The two different tool-pin geometries considered in this study are a threaded tri-flute conical tool-pin and an inverted conical threaded toolpin. The general shape of these tool-pin profiles is patented by TWI but were locally designed and manufactured.

However, irrespective of tool-pin geometry and shape of tool shoulder, the dwell time is considered an important technical parameter in the welding process to maximise the effective weld length hereby shortening the time (and distance) to reach weld stability. This implies that commencing the welding operation too soon after plunging, the time and distance to reach a stable threshold for a suitable weld will in fact be longer. Hence, the heat generated during the dwell phase must be high enough to ensure sufficient plasticity of the material in contact with the shoulder and tool-pin before traversing the tool in creating the weld. This resulted in less force was being applied on the tool during ramp-up (initial traverse) and hence will reduce the possibility of tool-pin breakage (failure). In this comparative study, the results show that by establishing the dwell time phase for the two tool-pin geometries, Fx and torque stabilised well within the set ramp-up distance of $20 \mathrm{~mm}$. Welds were conducted on a FSW I-Stir PDS platform.

\section{Materials and methods}

\subsection{Tool holder and tool-pins}

The tool holder and tool-pins (Fig. 1) were manufactured from W302 H13 tool steel and hardened to 556 HV hardness.
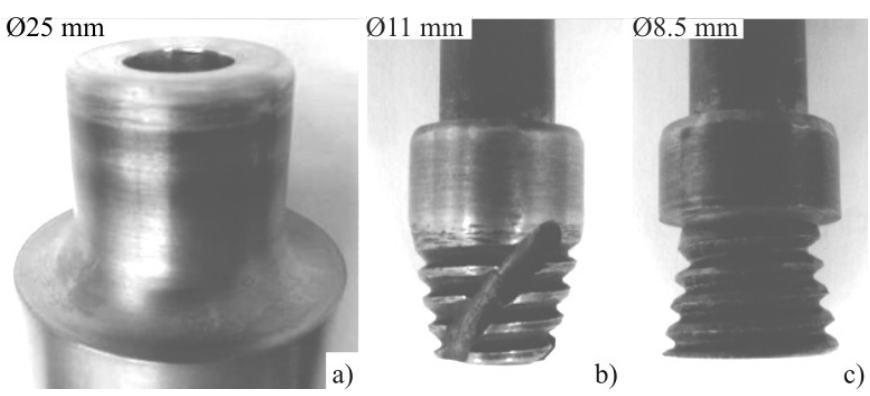

b)

c)

Fig. 1 Section of tool holder showing concave shoulder and rounded edge (a), and tool-pin geometries, threaded tri-flute conical tool-pin (b) and inverted conical threaded tool-pin (c).

The maximum and minimum root diameters of the threaded tri-flute conical and the inverted conical threaded (flare) toolpins were $11 \mathrm{~mm}$ and $8.5 \mathrm{~mm}$ respectively (see Fig. 1). Both tool-pin lengths were $7.6 \mathrm{~mm}$ and the threads were machined with a pitch of $1.5 \mathrm{~mm}$. Besides the thread, another re-entrant feature added was the flute to enhance the material mixing during welding. The tool holder has a shoulder diameter of $25 \mathrm{~mm}$, an outer edge radius of $2 \mathrm{~mm}$ and is concave shaped.

\subsection{Experimental procedure}

Welds were conducted 'bead-on-plate' and welded parallel to the rolling direction of the parent material. The material considered for this study was AA6082-T6 aluminium in T6 condition, $8 \mathrm{~mm}$ thick and cut to a sample size of $185 \mathrm{~mm} \times 120$ $\mathrm{mm}$. AA6082-T6 is a cheap and locally available material with medium strength (yield strength $\mathrm{Rp}_{0.2}=250 \mathrm{MPa}$ ). The dwell time was established by plunging each tool into a plate sample until the spindle torque reached stability (Fig. 2).

The welding mode considered was that of 'position control' and for this mode a tool tilt angle of $2^{\circ}$, a tool-pin plunge rate of $15 \mathrm{~mm} \cdot \mathrm{min}^{-1}$, a plunge depth of $7.8 \mathrm{~mm}$ allowing a shoulder plunge of $0.2 \mathrm{~mm}$, was used. The spindle speed was set at 600 $\mathrm{rpm}$ with a feed rate of $90 \mathrm{~mm} \cdot \mathrm{min}^{-1}$. The spindle torque as well as the plunge force, $F_{z}$, stabilised after 20 seconds for both tool-pin profiles. From Fig. 2 and considering stage (' $b$ '), the spindle torque increases as the tool-pin is forced into the material. During this stage the heat generated by the rotating toolpin creates localised plastic deformation increasing the flow stress of the material. This process continues during shoulder plunge where after the spindle torque decreases rapidly to a more stable value indicating that a threshold plasticised volume 


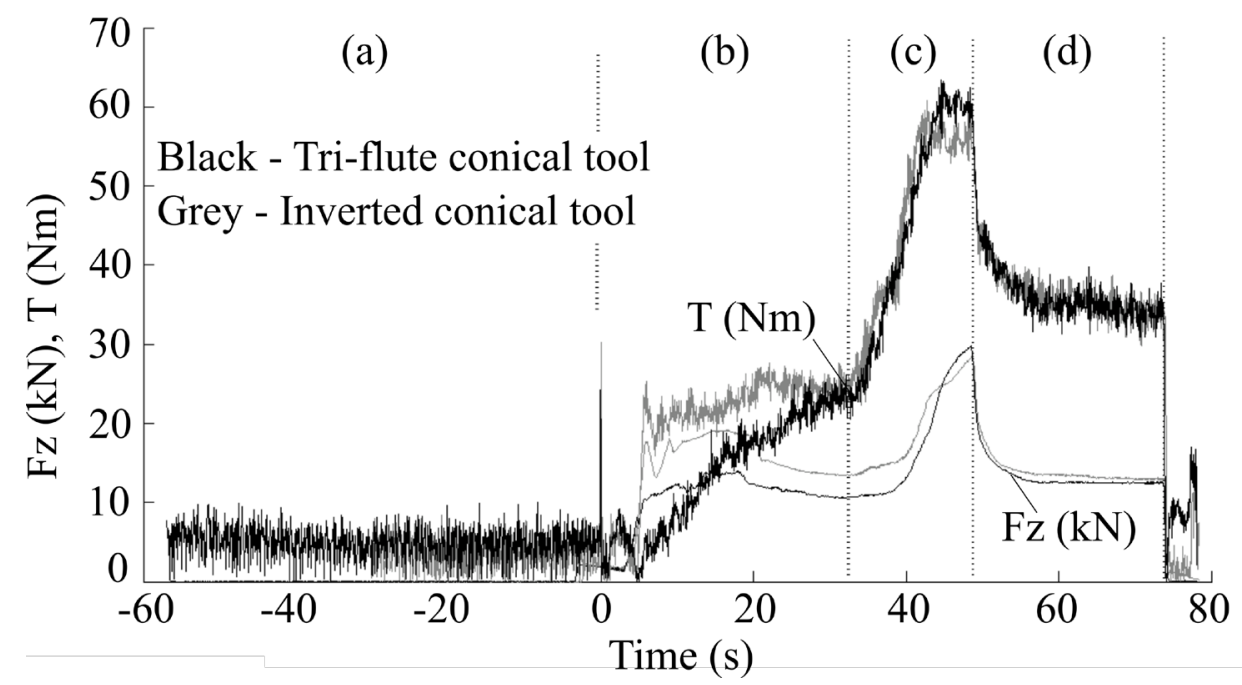

Fig. 2 Spindle torque $(T)$ and plunge force $\left(F_{z}\right)$ response to establish dwell time stability. Sections: (a) lowering of the spindle head until tool-pin contacts the weld material; (b) plunging the tool-pin into weld material; (c) shoulder contact with weld material; and (d) time to reach spindle torque stability (dwell time).

Black - Tri-flute conical tool Grey - Inverted conical tool

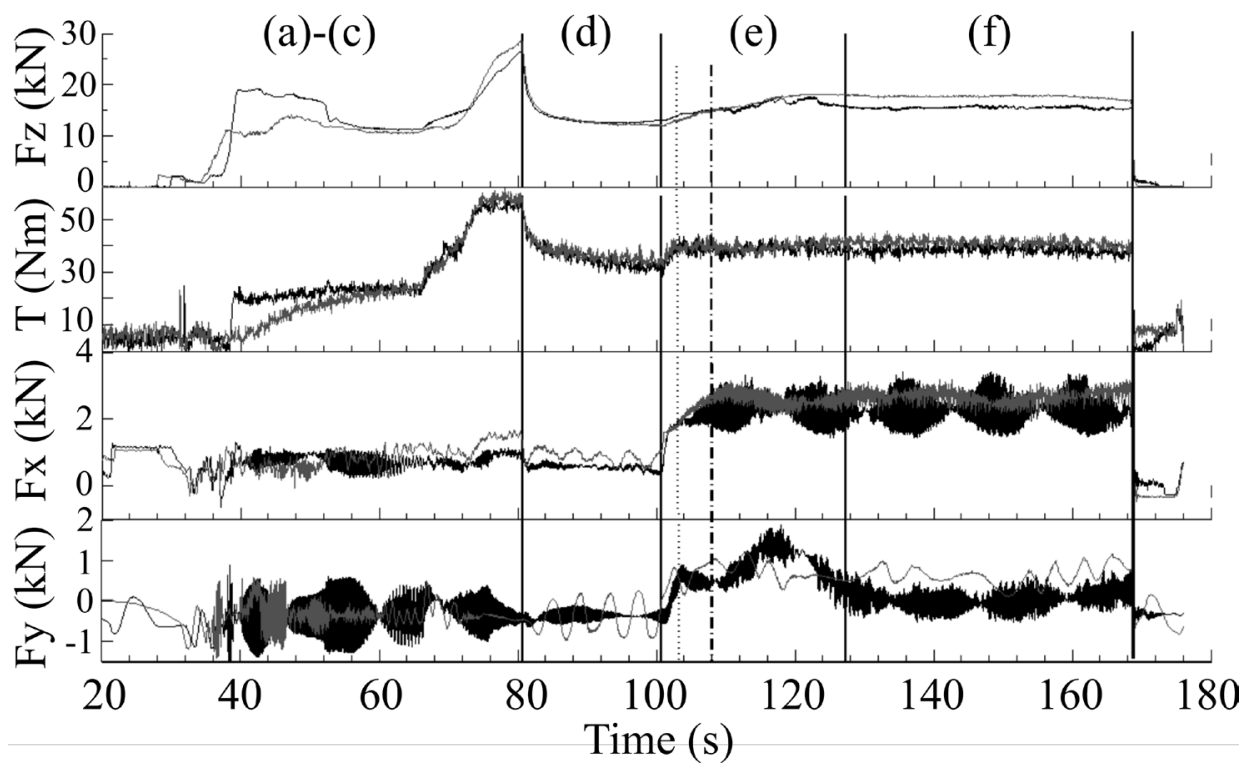

Fig. 3 Process responses - tool-pin plunge through weld and final tool-pin extraction. Sections: (e) is spindle torque stability zone and (f) is spindle torque stability zone with decreasing Fy force.

of material under the shoulder and around the tool-pins have been achieved. For tool-pin in Fig. 1 (b) the torque increases steadily because its profile assists the downward penetration of the tool-pin into the material. However, for tool-pin Fig. 1 (c) the initial plunge force, $F_{z}$, is approximately twice that of toolpin Fig. 1 (b) and approximately four times higher for spindle torque because of its greater foot area. Interesting to note is that the torque reaches a common threshold prior to shoulder plunge (last phase in stage ' $b$ '), which increases to approximately $60 \mathrm{Nm}$ before rapidly dropping to around $45 \mathrm{Nm}$ (stage ' $d$ ') before stabilising around $35 \mathrm{Nm}$, which considered as the steady-state value before the tool was retracted.

\section{Results and discussion}

\subsection{Process response during welding}

The response of both tool-pins with respect to: plunge force $\left(F_{z}\right)$, spindle torque $(T)$, weld force $\left(F_{x}\right)$ and side force $\left(F_{y}\right)$ are shown in Fig. 3. The time taken during ramp-up (acceleration period of the tool) and weld traverse (constant velocity period of the tool) was calculated at 26 and 46 seconds respectively applying fundamental mechanics equations. It is evident from Fig. 3 that all force responses are stable after 26 seconds and that $F_{x}$ for the inverted conical threaded tool-pin was marginally lower than that of the threaded tri-flute tool, implying that the former tool profile is slightly more efficient from a force 
response viewpoint. The forces $F_{z}$ and $F_{y}$ can be said to have stabilised at ramp-up (26 seconds). The spindle torque $(T)$ on the other hand stabilised approximately 3 seconds after commencement of ramp-up (shown by the dotted line in section (e) and the welding force $\left(F_{x}\right)$ after approximately 10 seconds (the dot-dashed line section (e) considering both tool-pins (Fig. 3).

The difference of surface areas for the two tool pins was approximately $5 \%$, which is also the approximate difference in average $F_{x}$. This implies that average $F_{x}$ values are approximately proportional to tool-pin surface areas. The sinusoidal histories' in weld force $\left(F_{x}\right)$ evident for both tool- pin geometries during ramp-up and weld is intriguing. Two hydraulic pressure sensors are used to monitor the force responses $F_{x}$ and $F_{y}$ giving two sinusoidal graphs $180^{\circ}$ out of phase. The cyclic forces response are believed to be due to the movement of material from the front edge of the tool towards the back end of the tool and makes the tool move in a periodic fashion [23]. Work by Hattingh et al. [24] used a force footprint to optimize tool performance and it was believed that the areas of the force footprint relate to heat input into the weld. It should be noted that $F_{x}$ increases as the feed rate is increased whereas the heat input decreases with increased feed rate.

Since the traverse (feed rate) for both tools used in this work were the same, a greater maxima and minima variation in $F_{x}$ would imply that less heat would have been induced into the weld. Hence, when the sensors measure similar $F_{x}$ values at the fore and rear end of the tool during a revolution a straight line graph would be expected suggesting that the material flow dynamics has achieved equilibrium. Researches showed [25] that $F_{x}$ could be used to minimize void formation in FSW, however high axial load values led to tool destruction [26].

\subsection{Micro and macro-structural observations}

After welding, each plate was sectioned in numerous locations along the weld length (Fig. 4) for microstructural and microhardness analyses.

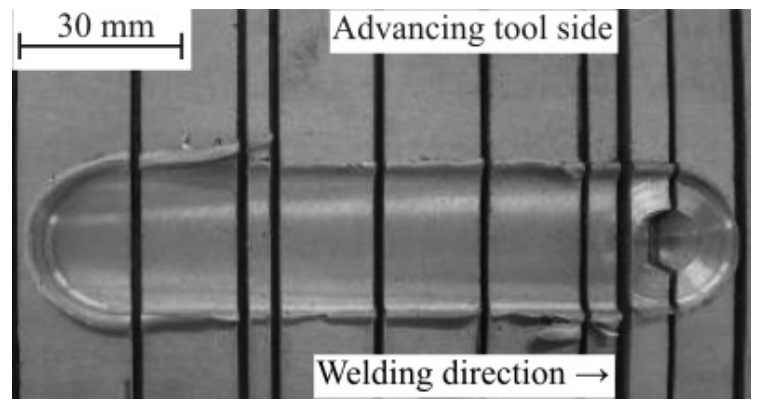

Fig. 4 Illustration of plate sectioning for the weld made with the tri-flute tool.

All weld samples were etched with sodium-hydroxide solution ( $1 \mathrm{~g}$ to $100 \mathrm{ml}$ distilled water) for a period of approximately 20 minutes to pronounce the FSW areas: heat affected zone (HAZ), thermo-mechanical affected zone (TMAZ) and nugget. The cross-section macrographs shown in Fig. 5 are of weld sections parts: (a) $20 \mathrm{~mm}$ from the beginning of the weld, (b) 40 $\mathrm{mm}$ from the beginning of the weld and (c) $30 \mathrm{~mm}$ from the end of the weld, which clearly show the effects of the FSW process; note that the plate thickness was $8 \mathrm{~mm}$ prior to welding.

The advancing tool side is seen on the right in all macrographs. This is the side of the tool that rotates in the same direction as the weld path.

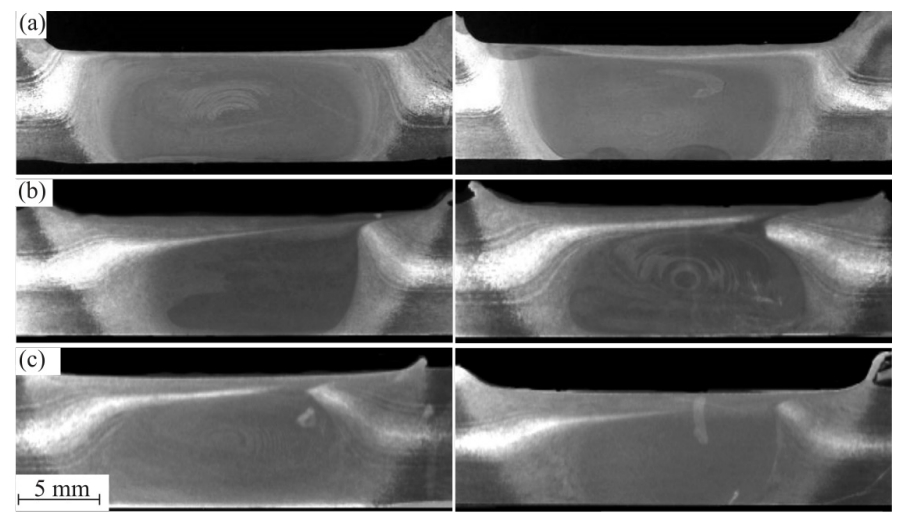

Fig. 5 Macrograph of cross-sections. (a): $20 \mathrm{~mm}$ from the beginning of the weld, dwell phase, (b): $40 \mathrm{~mm}$ from the beginning of the weld, after ramp-up and (c): $30 \mathrm{~mm}$ from the end of the weld line, before tool-pin extraction. Left column: tri-flute conical and right column: inverted conical pin geometry.

General observations are that the inverted conical threaded tool-pin ensures a better defined weld nugget and an evenly distributed TMAZ and HAZ around the nugget regions. Also, the weld features are similar in comparing Fig. 5 (b) and 5 (c) implying that indeed steady-state welding conditions were achieved. There also appears to be six distinct affected zones, i.e. (i) the shoulder stir zone (SSZ), (ii) a transition stir zone (TSZ) - seen between SSZ and nugget, (iii) the tool-pin stir zone (nugget), (iv) a thermo-mechanical affected zone (TMAZ), (v) the heat affected zone (HAZ) and (vi) the root stir zone (RSZ). At higher magnification, evidences of mixed zones are present in both welds as seen in Fig. 6 .
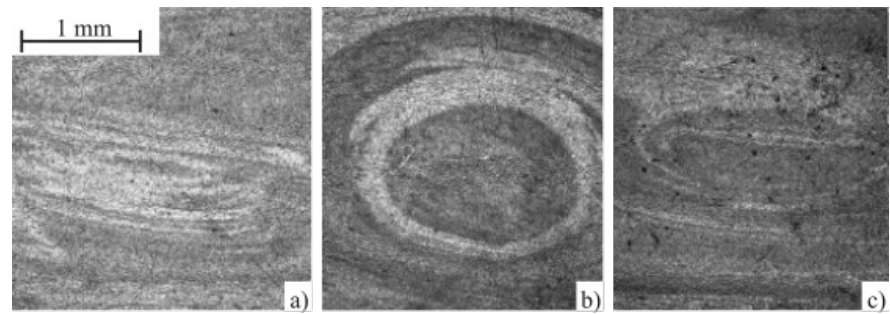

Fig. 6 Mixed zones, (a) as seen just below the nugget centre for the threaded conical tri-flute tool-pin weld, while that of the inverted conical threaded toolpin weld (b) in the centre of nugget area and (c) close to the RSZ.

Work by Dubourg et al. [14] suggests that a double nugget is due to instability of material mixing due to differences in velocities at top and bottom regions of the pin when the rpm is too large at the applied feed rate. In their study, the double 
nugget is observed to be adjacent to one another however, in our case study the double nugget lie one below the other.

Further investigation is required to determine whether this phenomenon translates into a strengthening mechanism. It should be noted that the ultimate objective of this study was not to determine optimum process parameters but to establish dwell time for effective maximum weld length usability since most FSW discard the initial portion of the weld.

\subsection{Microhardness analysis}

Micro Vickers hardness measurements (Fig. 7) were taken for each FSWs at locations indicated by the intersections of the dotted lines for the dwell, ramp-up and weld sections: $40 \mathrm{~mm}$ from the beginning of the weld and $30 \mathrm{~mm}$ from the end of the weld.

The hardness locations (Fig. 8) were 1, 4 and $7 \mathrm{~mm}$ from the top surface of the welds indicated as lines 1, 2 and 3. The hardness values are given in Table 1 . The reason for determining the hardness in this particular sequence was to establish whether or not the whole weld length can be considered as useful.

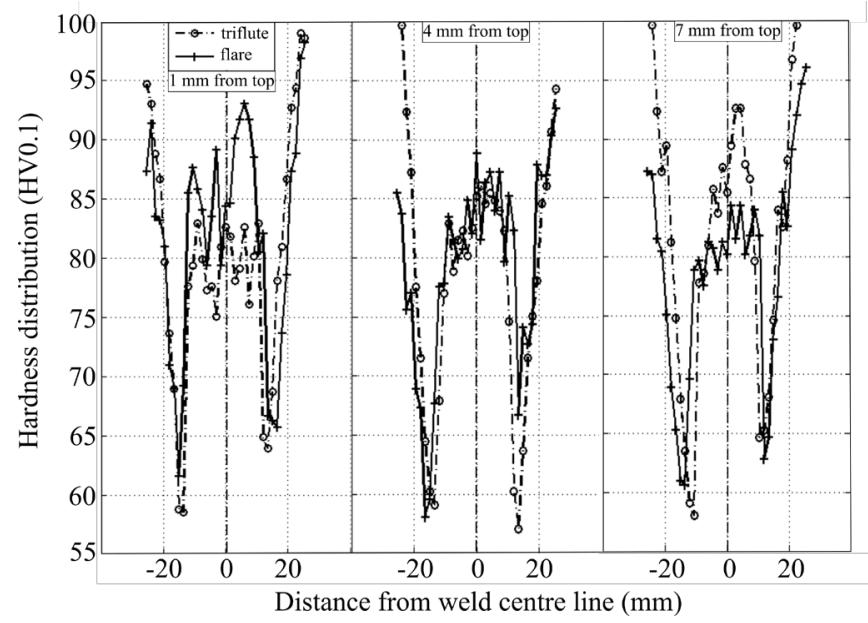

Fig. 7 Hardness measurements of cross-section $40 \mathrm{~mm}$ from the beginning of the weld (dwell section.), $1 \mathrm{~mm}, 4 \mathrm{~mm}$ and $7 \mathrm{~mm}$ from the top surface from left to right (lines 1, 2 and 3 respectively on Fig. 8). The average HV0.1 hardness of the AA6082-T6 base material was $110 \pm 7$.

This would also substantiate the hypothesis, as mentioned earlier, for ascertaining the time to reach spindle torque stability (equilibrium) during dwell. For this to be considered true
Table 1 HV0.1 values for welds made with tri-flute and flare tool-pins.

\begin{tabular}{lcccccc}
\hline \multicolumn{5}{c}{ Flared tool-pin weld HV0.1 hardness values } \\
\hline & A & B & C & D & E & Av. \\
1 & 73 & 83 & 81 & 80 & 82 & 80 \\
2 & 87 & 84 & 91 & 84 & 85 & 86 \\
3 & 83 & 96 & 95 & 84 & 86 & 89 \\
Av. & 81 & 88 & 89 & 83 & 85 & - \\
\hline Tri-flute tool-pin weld HV0.1 hardness values \\
\hline 1 & 80 & 80 & 82 & 83 & 91 & 83 \\
2 & 82 & 83 & 84 & 84 & 95 & 86 \\
3 & 95 & 95 & 94 & 85 & 92 & 92 \\
Av. & 86 & 86 & 87 & 84 & 93 & - \\
\hline
\end{tabular}

the hardness should not vary substantially between locations A, B, C, D and E (Fig. 8) as well as through the thickness planes at these locations 1, 2 and 3 (Fig. 8).

At $1 \mathrm{~mm}$ below the top surface the hardness values of the welded material produced by both tools were lowest at location 1 (Fig. 8). This is to be expected as the tool shoulder provides the over ageing heat source. At location 3 of Fig. 8, the hardness values are higher as the only heat source is that of the lower end of the tool-pins. This observation is attributed to the tangential velocities at the bottom of each tool-pin in that the diameters are opposite at these planes, i.e. where the diameter is $8.5 \mathrm{~mm}$ the tangential velocity is $0.267 \mathrm{~m} \cdot \mathrm{s}-1$ and at the 11 $\mathrm{mm}$ diameter plane it is $0.346 \mathrm{~m} \cdot \mathrm{s}-1$. Hence, more heat is generated at the plane where the tool-pin diameter is largest. This is also evident in Fig. 8 considering positions 1 and 3. A decrease in hardness values were measured in the TMAZ of both welds compared to the surface hardness of the parent material, which is a typical trend for aluminium FSW welds.

A numerical analysis of dwell phase was also conducted by Gemme et al. [27] on $2 \mathrm{~mm}$ thick 7075-T6 aluminium alloys using three different process parameters but failed to use the established spindle torque stability dwell time of 15 seconds. Their findings showed no correlation between experimental data and the numerical analysis undertaken except to note that the maximum spindle torque reached was lower at higher spindle speed, a condition that is to be expected.

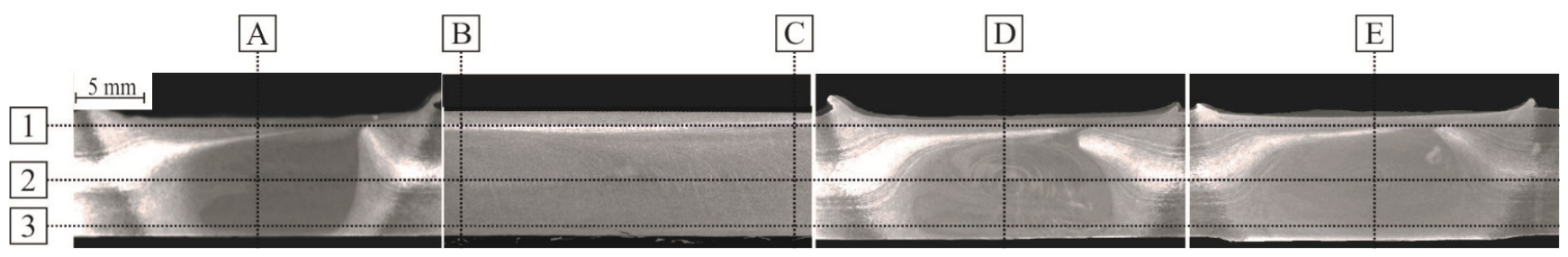

Fig. 8 HV0.1 hardness measurement locations (flared tool-pin). A: centre of dwell section (20 mm from the beginning of the weld), B and C: 2 mm inside from the tool shoulder of the ramp-up section ( $30 \mathrm{~mm}$ from the beginning of the weld) and $\mathrm{D}$ and $\mathrm{E}$, centre of weld sections $40 \mathrm{~mm}$ from the beginning and $30 \mathrm{~mm}$ from the end of the weld line, respectively. 


\section{Conclusion}

The time and distance to reach welding stability for both welds considering the force exerted on the tool-pins $\left(F_{x}\right)$ was 10 seconds and $8 \mathrm{~mm}$ respectively (given the welding feed rate of $90 \mathrm{~mm} \cdot \mathrm{min}^{-1}$ ) at a dwell time of 26 seconds (Fig. 3).

The inverted conical threaded tool-pin ensures a better defined weld nugget and an evenly distributed TMAZ and HAZ around the nugget regions. At higher magnifications the evidence of mixed zones are visible (Fig. 6).

In every location of the welds made with both pin-tool geometries a slight decreased was measured in the HV0.1 hardness distribution. The reason of this is the T6 condition of the base metal, which was plasticized and homogenized during the welding. This decreasing was higher in case of flared tool- pin, as the higher diameter means higher tangential velocity and more heat is generated.

From our research, further presumptions can be done. For FSW in the 'position control' mode it is important to establish dwell time through spindle torque stability ensuring that the distance and time to reach weld force stability $\left(F_{x}\right)$ will be a minimum to maximise weld length. Under 'force control' mode the tool-pin would have penetrated further into the material [28] and perhaps into the backing plate because of increased plasticisation under the tool shoulder due to the extended dwell time as reported in this study. No relationship was found to exist between the set ramp-up distance $(20 \mathrm{~mm})$ and distance to reach weld stability $(8 \mathrm{~mm})$. One can further conclude that a concave shoulder contains a larger volume of plasticised material because of the minimum flash produced during welding which is considered an advantage.

\section{Acknowledgement}

The authors wish to thank the following for their assistance:

- The Manufacturing Technology Research Centre (MTRC), Nelson Mandela Metropolitan University (NMMU), Port Elizabeth, South Africa, for the use of the friction stir welding platform and mechanical testing equipment.

- The Nelson Mandela Metropolitan University and the National Research Foundation (NRF), Pretoria, South Africa, for their financial support.

\section{References}

[1] Thomas, W. M., et. al. The Welding Institute, 1991. TWI, International Patent Application No. PCT/GB92/02203 and GB patent Application No. 9125978.8 .

[2] Singh, J., Singh, H. "Recent trends and application of Friction stir welding: A Review." International Academy of Engineering and Medical Research. 1(1), pp. 1-3. 2016.

[3] Hattingh, D. G., von Welligh, L. G., Bernard, D., Susmel, L., Tovo, R., James, M. N. "Semiautomatic friction stir welding of 38mm OD 6082T6 aluminium tubes." Journal of Materials Processing Technology. 238, pp. 255-266. 2016.

https://doi.org/10.1016/j.jmatprotec.2016.07.027
[4] Gopi, S., Manonmani, K. "Predicting tensile strength of double side friction stir welded 6082-T6 aluminium alloy." Science and Technology of Welding and Joining. 17(7), pp. 601-607. 2012.

https://doi.org/10.1179/1362171812y.0000000055

[5] Darji, B. B., Tandel, M. M., Patel, J. B. "Friction stir Welding of Edge joint on similar Aluminum Alloys 6082 and Analysis of Flow stress and Temperature." IJISET - International Journal of Innovative Science, Engineering \& Technology. 1(5), pp. 257-259 2014.

[6] Thimmaraju, P., Arkanti, K., Reddy, G. C., Tilak, K. B. G. "Comparison of Microstructure and Mechanical Properties of friction Stir welding of Al 6082 aluminum alloy with different Tool Profiles." Materials Today: Proceedings. 3(10), pp. 4173-4181. 2016. https://doi.org/10.1016/j.matpr.2016.11.092

[7] Cho, J.-H., Kim, W. J., Lee, C. G. "Evolution of Microstructure and Mechanical Properties During Friction Stir Welding of A5083 and A6082." Procedia Engineering. 81, pp. 2080-2085. 2014. https://doi.org/10.1016/j.proeng.2014.10.289

[8] Hamada, A. S., Järvenpää, A., Ahmed, M. M. Z., Jaskari, M., Wynne, B. P., Porter, D. A., Karjalainen, L. P. "The microstructural evolution of friction stir welded AA6082-T6 aluminum alloy during cyclic deformation." Materials Science and Engineering: A. 642, pp. 366-376. 2015. https://doi.org/10.1016/j.msea.2015.06.100

[9] Wan, L., Huang, Y. X., Guo, W., Lv, S., Feng, J. "Mechanical Properties and Microstructure of 6082-T6 Aluminum Alloy Joints by Self-support Friction Stir Welding." Journal of Materials Science and Technology. 30(12), pp. 1243-1250. 2014.

https://doi.org/10.1016/j.jmst.2014.04.009

[10] Jamshidi Aval, H. "Influences of pin profile on the mechanical and microstructural behaviours in dissimilar friction stir welded AA6082-AA7075 butt joint." Materials \& Design. 67, pp. 413-421. 2015. https://doi.org/10.1016/j.matdes.2014.11.055

[11] Scialpi, A., De Filippis, L. A. C., Cavaliere, P. "Influence of shoulder geometry on microstructure and mechanical properties of friction stir welded 6082 aluminium alloy." Materials \& Design. 28(4), pp. 11241129. 2007

https://doi.org/10.1016/j.matdes.2006.01.031

[12] Costa, M. I., Verdera, D., Leitão, C., Rodrigues, D. M. "Dissimilar friction stir lap welding of AA 5754-H22/AA 6082-T6 aluminium alloys: Influence of material properties and tool geometry on weld strength." Materials \& Design. 87, pp. 721-731. 2015. https://doi.org/10.1016/j.matdes.2015.08.066

[13] Van Haver, W., Stassart, X., de Meester, B., Dhooge, A. "Friction Stir Welding of Aluminum High Pressure Die Castings: Parameter Optimisation and Gap Brigeability." Welding in the World. 52(9-10), pp. 20-29. 2008. https://doi.org/10.1007/BF03266665

[14] Dubourg, L., Jahazi, M., Gagnon, F. O., Nadeau, F., St-Georges, L. "Process window optimization for FSW for thick and thin sheet Al alloys using statistically methods." In: 6th International Symposium of Friction Stir Welding, St Sauveur, QC, Canada, Oct. 10-13, 2006, pp. 419-430.

[15] Dawes, C. J. "Faster and faster welding speed increases with tool development - one of a series of steps." TWI Bulletin. 41(4), pp. 51-55. 2000.

[16] Arbegast, W. J., Mirshra, R. S., Mahaney, M. W. "Friction Stir Welding and Processing." ASM International, Materials Park, OH. pp 273-308. 2007.

[17] Arbegast, W. J. "Using process forces as a statistically process control tool for friction stir welds." In: Friction Stir Welding and Processing III, TMS Annual Meeting, San Diego, CA, 2-6 March, 2003, pp. 313-327.

[18] Mulenga, A. P. "Analysis of weld gap variation on Friction Stir joint integrity." Dissertation. Mechanical Engineering, Nelson Mandela Metropolitan University, Port Elizabeth, South Africa, 2008.

[19] Moriaki, O., Yukio, S., Akihide, Y., Masanori, O. "Development of laserarc hybrid welding." NKK Technical Review. 86, 2002. 
[20] Inada, K., Fujii, H., Ji, Y. S., Sun, Y. F., Morisada, Y. "Effect of gap on FSW joint formation and development of friction powder processing." Science and Technology of Welding and Joining. 15(2), pp. 131-136. 2010. https://doi.org/10.1179/136217109X12568132624244

[21] Krasnowski, K. "Technology of friction stir welding of aluminium alloy 6082 T-joints and their behaviour under static and dynamic loads." Materialwissenschaft und Werkstofftechnik. 46(3), pp. 256-268. 2015. https://doi.org/10.1002/mawe.201400320

[22] Meilinger, Á., Török, I. "The importance of friction stir welding tool." Production Processes and Systems. 6(1), pp. 25-34. 2013.

[23] Burford, D. A., Tweedy, B. M., Widener, C. A. "Influence of shoulder configuration and geometric features on FSW track properties." In: 6th International Symposium of Friction Stir Welding, St Sauveur, QC, Canada, Oct. 10-13, 2006, pp. 1-12.

[24] Hattingh, D. G., van Niekerk, T. I., Blignault, C., Kruger, G., James, M. N. "Analysis of the FSW force footprint and its relationship with process parameters to optimise weld performance and tool design." Welding in the World. 48(1-2), pp. 50-58. 2004.

https://doi.org/10.1007/BF03266414
[25] Sajan, G. S., Meshram, M., Pankaj, Srinivas, P., Dey, S. R. "Friction stir welding of aluminium 6068 with mild steel and its joint analyses." International Journal of Advanced Materials Manufacturing and Characterization. 3(1), pp. 1-6. 2013.

https://doi.org/10.11127/ijammc.2013.02.033

[26] Rodrigues, D. M., Leitão, C., Louro, R., Gouveia, H., Loureiro, A. "High speed friction stir welding of aluminium alloys." Science and Technology of Welding and Joining. 15(8), pp. 676-681. 2010. https://doi.org/10.1179/136217110X12785889550181

[27] Gemme, F., Verreman, Y., Dubourg, L., Jahazi, M. "Numerical analysis of the dwell phase in friction stir welding and comparison with experimental data." Materials Science \& Engineering: A. 527(16-17), pp. 4152-4160. 2010.

https://doi.org/10.1016/j.msea.2010.03.026

[28] Campanella, D., Russo Spena, P., Buffa, G., Fratini, L. "Dissimilar Al/steel Friction stir welding lap joints for automotive applications." American Institute of Physics Conference Proceedings. 1769, pp. 100005-1-100005-6. 2016.

https://doi.org/10.1063/1.4963499 